\title{
Autonomia universitária e integração da América Latina: o papel da UDUAL
}

\author{
José TADEU JORGE
}

Ex rector Universidade Estadual de Campinas y ex presidente de UDUAL

A realização do Primeiro Congresso de Universidades Latinoamericanas, em setembro de 1949, na Guatemala (apenas pelo fato concretizado), já poderia ser considerado um avanço considerável para as relações entre as universidades e para a criação de referências que visassem ao desenvolvimento das instituições existentes. Convocado pela Universidad de San Carlos, a iniciativa do Instituto Americano de Relaciones e Investigaciones Universitarias de Santiago de Chile, reuniu 24 universidades de países da América Latina. Em seu discurso de boas vindas, ao referir-se à ausência de representantes das universidades que não puderam comparecer ao evento, o doutor Carlos Martínez Durán, com palavras muito adequadas, previu: "Para las Universidades ausentes, queda abierta, franca y leal, la puerta del entendimento comprensivo".

O congresso, entretanto, iria muito mais além. Estabeleceria a criação e as bases constitutivas da Unión de Universidades Latinoamericanas, que adotaria, posteriormente, a sigla UDUAL. O texto aprovado traçava as finalidades do novo organismo internacional, dentre elas, o alicerce mais fundamental: "propender a la implantación por todas las Universidades Latinoamericanas, de los principios universitarios de libertad en la investigación y en la cátedra y de plena autonomia”. Tal objetivo mostrava total sintonia com os princípios balizadores do evento, também expressos nas palavras de recepção aos participantes: "es imprescindible el ambiente político favorable, el clima de una libertad alta e hermosa. Y en el caso especial de la Universidad, ésta debe gozar de autonomia plena, formal y patrimonial".

Os ideais de integração da América Latina, assim como o papel social das universidades, também foram estabelecidos de maneira clara e propositiva nas finalidades da nova entidade associativa: "contribuir a la realización en el plano internacional, de los ideales de unidad de la América Latina y en el orden nacional de los postulados de organización democrática, de respeto a la dignidad humana y de justicia social".

Ainda, um último destaque entre as finalidades: "propender a la orientación, coordinación y, en lo posible, a la unificación básica de la organización académica y administrativa de las Universidades de Latinoamérica, sin perjuicio de conservar e incluso acentuar las diferencias propias del medio en que actúan”. Enfatize-se a referência textual e direta à unificação da organização acadêmica, certamente, uma visão muito avançada para os padrões da época e, digamos, quase profética.

Necessário voltar às palavras do doutor Carlos Martínez Durán na abertura dos trabalhos do Primeiro Congresso de Universidades Latinoamericanas para entender 
a disposição e os propósitos que fizeram nascer a UDUAL: "Nada despierta tanto la simpatía y el afecto, fortifica la comprensión y anima alegrías, como trabajar juntos para crear, para superarse. Así este Congreso es punto de partida para nuevas e renovadas etapas en la unidad espiritual de América".

Embora os Estatutos atuais da UDUAL tenham outra redação, sejam mais abrangentes e melhor adaptados ao mundo de hoje, as concepções de origem permanecem fundamentalmente as mesmas.

\section{Setenta anos depois, como estamos?}

Tendo como certo de que não é possível responder tal pergunta analisando todos os aspectos existentes, abordaremos suscintamente três temas que nos parecem essenciais nos dias de hoje: autonomia, produção de conhecimento para benefício da sociedade e integração acadêmica.

E, em marcos comemorativos como quando uma instituição completa 70 anos, torna-se oportuno analisar uma outra questão: para onde devemos ir?

\section{Autonomia}

Alguns meses antes da criação efetiva da UDUAL, janeiro de 1949, em documento intitulado Proposición sobre la autonomía, Luis Alberto Sánchez abordava o tema, ressaltando dois aspectos: as relações das universidades com o Estado e o desenvolvimento das próprias universidades. Destaca em suas análises a diversidade de situações existentes nos países latino-americanos, com algumas universidades plenamente autônomas ao lado de outras sem nenhuma autonomia. Entre esses extremos, várias universidades com distintos graus de liberdade, que denominou de semiautônomas. Relaciona, de certa forma, a existência de universidades autônomas com a democracia vigente nesses países, que aponta como condição importante para estabelecer a devida sintonia das instituições com relação às necessidades sociais e de desenvolvimento. Conceitualmente, defendia um modelo de autonomia que englobava as atividades pedagógicas, financeiras, administrativas e doutrinais. Concluía por propor que o Congresso de Universidades Hispano-Americanas aprovasse uma resolução, cujo ponto mais relevante indicava o estabelecimento constitucional da autonomia universitária.

Embora o conceito, a abrangência e os limites da autonomia universitária sejam discutidos há séculos, é certo que o século XX marcaria a tendência de dar formato legal ao tema, especialmente, no sentido de adotá-lo como um princípio estabelecido nas leis maiores de cada país. Valadés (2014, p. 27, 28 e 36) analisa esse período com adequado foco nos países da América Latina e demonstra claramente o crescimento do número de países em que a constituição passou a incorporar dispositivos que garantem a autonomia das universidades. Faz referência a 17 países da região que incluem em suas constituições os princípios da autonomia universitária, desde a simples garantia do princípio até detalhamentos mais elaborados sobre compromissos e balizamentos. Ao analisar a regulamentação constitucional mexicana e o histórico de adaptação das instituições envolvidas, 
expressa uma constatação que, certamente, pode ser extrapolada para todos os países latino-americanos e que merece ser lembrada e destacada:

La adaptación de las normas relativas a la autonomía universitaria no ha sido fácil. Las comunidades académicas han tenido que aprender a distinguir entre las reglas de las comunidades políticas y las que rigen a las comunidades académicas. Los principios agonistas de competencia y de lucha de la sociedad política no son los propios de un espacio donde se utiliza el diálogo e incluso el debate para construir el saber y no para disputar el poder.

Em que pesem todas as dificuldades práticas e operacionais encontradas nos processos de autonomia, é fato indiscutível que os avanços registrados são muito significativos. E não é difícil demonstrar que universidades realmente autônomas contribuem de maneira mais efetiva e decisiva para melhorar as condições sociais das pessoas e para produzir conhecimentos que gerem melhor qualidade de vida e propiciem mais liberdade a cada indivíduo.

Ao associarem ensino, pesquisa e extensão, as universidades viabilizam aos profissionais formados empregos mais qualificados e renda mais significativa, geram conhecimentos que são convertidos em serviços e produtos mais eficientes e eficazes e estão sempre em sintonia com as necessidades sociais, desde as mais imediatas até aquelas que ainda demandam aperfeiçoamentos.

Muito oportuna a conclusão de Cantard (2014, p. 75): "las políticas de investigación orientadas al mejoramiento de la calidad de vida social permiten generar herramientas científicas y tecnológicas de mayor incidencia en el bienestar de la población, en el fortalecimiento de la democracia, en la reafirmación de las igualdades y de la concreción de un desarrollo sustentable".

Foi a criação da UDUAL que impulsionou de maneira mais organizada a demanda pela autonomia universitária na América Latina no século passado. É certo que existiam antes algumas universidades que já se regiam por esse princípio, mas as ações estabelecidas a partir de então permitiram divulgar essas experiências e dar a elas mais visibilidade, tanto no meio acadêmico como, principalmente, fora dele, em especial, junto aos governos e à opinião pública. O papel agregador desempenhado pela UDUAL foi decisivo para disseminar a ideia e os argumentos que poderiam ser aportados para defender o princípio e esclarecer as vantagens da efetiva implantação da autonomia universitária.

Ao longo do tempo, os fatos mostram a fidelidade da UDUAL às suas origens, com ações concretas em defesa da autonomia universitária em seus textos, eventos, reuniões e publicações. Isso foi e continua sendo absolutamente necessário, uma vez que motivações ideológicas e mercadológicas aparecem constantemente como ameaças a esse pilar de sustentação das universidades. Devido a contextos assim, em setembro de 2012, a Declaración de Guadalajara sobre Autonomía Universitaria, novamente reafirmou suas convicções a respeito da autonomia como princípio indispensável para as universidades. Mesmo decorridos quase sete anos, nunca é demais 
relembrar seu conteúdo, em nome da eterna vigilância que esse princípio merece:

Nos pronunciamos por continuar la defensa de la autonomía universitaria, valor que está siendo amenazado no sólo en México sino a lo largo y ancho de América Latina y el Caribe. En este sentido, fortaleceremos el Observatorio de la Autonomía Universitaria concebido como un espacio para compartir visiones y experiencias sobre este asunto en la región latinoamericana y del Caribe. Por otra parte, asumimos la necesidad de redefinir su concepto para adecuarlo a las circunstancias del presente. Hoy, autonomía universitaria significa: a) El fortalecimiento de la independencia, la legitimidad y la eficacia de los órganos colegiados que gobiernan la vida interna de las universidades; b) El reconocimiento de prerrogativas presupuestarias, por parte de los gobiernos nacionales, que permitan la planeación universitaria a mediano plazo, la certidumbre laboral y la plena vigencia de los derechos laborales de los profesores y empleados universitarios; c) El reconocimiento de las libertades de cátedra, investigación y creatividad humanística de los universitarios; d) El garantizar el financiamiento público de la educación superior como un derecho constitucional que corresponde observar más allá de la aplicación de criterios político-gubernamentales de carácter interesado. En otras palabras, la exigencia de rendición de cuentas a la universidad no debe utilizarse como pretexto para coartar la autonomía universitaria de ninguna manera, exigencia que no va en menoscabo de nuestro compromiso con la calidad en el ejercicio de nuestras funciones; e) Contar con espacios seguros que garanticen la libertad de la comunidad universitaria, en el contexto de los escenarios de inseguridad que actualmente se presentan en México (UDUAL, 2014, p. 22 e 23).

\section{Produção do conhecimento para benefício da sociedade}

Dentre as finalidades da UDUAL encontra-se o fomento às atividades que permitam integrar graduação, pós-graduação, pesquisa e às ações que gerem a transferência e difusão do conhecimento produzido. Tais objetivos, sintonizados com o papel social definido para as universidades, em especial aquelas que se sustentam com recursos públicos, resultam em estímulos fundamentais para que essas instituições busquem contribuir com inovações que possam equacionar adequadamente os grandes problemas vivenciados pela sociedade.

No que diz respeito à América Latina, a importância do trabalho realizado pelas universidades públicas é particularmente decisiva, uma vez que os outros agentes da inovação, as empresas e o setor privado, pouco investem e atuam. Em um cenário como esse a existência de articulações otimiza os esforços e geram resultados mais adequados. As redes universitárias propiciam oportunidades de atuação conjunta, com elevada sinergia e maior relação benefício-custo.

A heterogeneidade latino-americana mostra-se em toda sua plenitude quando o tema analisado é o sistema de ciência e tecnologia existente em 
cada país da região. O aspecto mais basilar, evidentemente, é o financiamento. Em média, os países da região investem em seus sistemas, por ano, entre 0,7 e 0,8\% do pib. Embora esses investimentos estejam crescendo ao longo dos anos, ainda estão muito distantes daqueles existentes em países da Europa, China, Canadá, Estados Unidos e, mais ainda, dos que mais investem por esse critério, como Coreia do Sul, Finlândia e Israel. Há enormes diferenças entre os países da América Latina. Enquanto o Brasil aplica algo em torno de $1,2 \%$ do PIB, a Argentina, que vem a seguir, está na faixa de 0,6-0,7\%; Costa Rica, México, Chile e Uruguai situam-se na faixa 0,4$0,5 \%$, e todos os demais abaixo desses patamares. Em outra análise, Brasil, México e Argentina representam cerca de 90\% dos investimentos realizados em ciência, tecnologia e inovação nos países latino-americanos.

Como consequência, o número de artigos científicos publicados mantém, aproximadamente, a mesma relação, com Brasil, México, Argentina e Chile respondendo por cerca de $90 \%$ do total. Além disso, o impacto das publicações feitas pelos países da América Latina é pequeno, significativamente abaixo da média mundial. Cabe destacar, ainda, que esse impacto aumenta quando os artigos possuem coautoria internacional, especialmente quando as parcerias são com pesquisadores dos países que mais publicam. As colaborações internacionais tem crescido ao longo dos últimos anos. Cerca de $45 \%$ das publicações da Argentina e do México possuem colaboração internacional, assim como 32\% das brasileiras. Os principais parceiros do Brasil nas publicações com coautoria são: Estados Unidos, Reino Unido, França, Espanha e Alemanha. O primeiro país da América Latina a aparecer nessa lista é a Argentina (posição 11), seguindo-se, Colômbia (14), México (15) e Chile (17) (Clarivate Analytics, 2017, p. 14, 24 e 26).

A situação exemplificada pelo Brasil não deve diferir muito das existentes nos outros países parceiros da região. Esse fato deve merecer atenção especial nas políticas de estímulo à integração da América Latina, pois incrementar essa colaboração pode ser essencial para atingir os objetivos propostos. Além disso, considerando que a América Latina abriga cerca de 5 a $6 \%$ da população mundial, os investimentos em ciência, tecnologia e inovação podem ser considerados insuficientes, uma vez que se situam um pouco acima dos $3 \%$ do total investido em todo o mundo.

Produzir conhecimento e inovações depende diretamente da existência de doutores em quantidades expressivas. Isso é consequência de um sistema de pós-graduação bem estruturado, além de financiamento adequado. Aqui reside outra deficiência latino-americana.

Enquanto vários países europeus, Austrália, Estados Unidos, Nova Zelândia e Coreia do Sul formam centenas de doutores por milhão de habitantes a cada ano; Israel, Canadá, Japão e outros países europeus situam-se no patamar de mais de uma centena; os países da América Latina mais bem posicionados nesse critério, Brasil, México, Chile e Argentina formam algumas (poucas) dezenas de doutores por milhão de habitantes a cada ano (CAPES/MEC, <http://www.clicrbs.com.br/pdf/17554144.pdf >).

Essa questão é preocupante, pois a prioridade dos países da região não parece ser a pós-graduação, como aponta o Informe 2015 sobre educação superior em Iberoamérica, editado pelo Centro Interuniversitario de Desarrollo (CINDA): 
Tradicionalmente la matrícula universitaria se ha centrado en el grado, y tal dinámica ha aumentado en los últimos años al calor de la expansión de la cobertura que ha reforzado el modelo de formación profesional, disminuyendo la incidencia relativa de la matrícula de maestrías y doctorados. Así, para el caso particular de América Latina, este nivel, que representó el 3\% del total de la matrícula en 1998, bajó al 2\% entre 1999 y el 2001, y desde el 2002 hasta el 2011 se volvió a reducir para quedar en el 1\%, según la información del Instituto de Estadística de la UNESCO (Barro, 2015, p. 104).

Dessa forma, sem financiamento adequado e com pequena formação de profissionais qualificados para a produção do conhecimento, a América Latina se encontra diante de enormes desafios, que precisam ser enfrentados para evitar uma distância ainda maior a nos separar dos países mais desenvolvidos.

\section{Integração acadêmica}

Há setenta anos, ao estabelecer as finalidades da UDUAL, o documento fundacional explicitava que a nova entidade deveria contribuir para "a unificação básica da organização acadêmica". Mostrava-se evidente a intenção de integrar a região latino-americana através da educação superior, não sem ressaltar os cuidados necessários para a preservação das riquezas de cada país em relação aos aspectos culturais e históricos.

Não é difícil constatar que a proposta, apresentada em 1949, mostrava uma teórica visão de futuro, expressava muito mais um desejo do que um projeto que pudesse ser executado com base em esforços e dedicação. A finalidade colocada sobre os ombros da UDUAL seria instituir no âmbito da América Latina algo como o acordo que se materializou na Europa quase cinquenta anos depois, com a assinatura da Declaração de Bologna, em 1999, que criou o Espaço Europeu de Educação Superior. Inicialmente constituído por 29 países (hoje conta com 48), a implantação foi considerada concluída em 2010, quase onze anos depois de iniciada. Ressalte-se que as tratativas que viabilizaram as assinaturas dos Ministros da Educação no documento de Bologna começaram, pelo menos, mais de uma década antes.

$\mathrm{Na}$ América Latina, a semente plantada no documento de criação da UDUAL permaneceu latente durante décadas. Entretanto, a dimensão e o impacto provocado pelo processo de Bologna fizeram renascer o desejo e o tema voltou à pauta dos meios universitários latino-americanos. Apenas em 2008, com a realização da Conferência Regional de Educação Superior na América Latina e Caribe, em Cartagena de Indias, Colômbia, a questão volta a ser tratada em condições mais objetivas. A declaração resultante do citado evento estabelece:

Es fundamental la construcción de un Espacio de Encuentro Latinoamericano y Caribeño de Educación Superior (ENLACES), el cual debe formar parte de la agenda de los gobiernos y los organismos multilaterales de carácter regional. Ello es básico para alcanzar niveles superiores que apun- 
ten a aspectos fundamentales de la integración regional: la profundización de su dimensión cultural; el desarrollo de fortalezas académicas que consoliden las perspectivas regionales ante los más acuciantes problemas mundiales; el aprovechamiento de los recursos humanos para crear sinergias en escala regional; la superación de brechas en la disponibilidad de conocimientos y capacidades profesionales y técnicas; la consideración del saber desde el prisma del bienestar colectivo; y la creación de competencias para la conexión orgánica entre el conocimiento académico, el mundo de la producción, el trabajo y la vida social, con actitud humanista y responsabilidad intelectual (IESALC/UNESCO, 2008).

O Plano de Ações proposto especifica em uma de suas cinco diretrizes: "promover la integración regional latinoamericana y caribeña y la internacionalización de la educación superior en la región mediante, entre otras iniciativas, la construcción del Espacio de Encuentro de América Latina y el Caribe para la Educación Superior (ENLACES)" (IESALC/UNESCO, 2008).

Após a realização da Conferência Mundial de Educação Superior, realizada em Paris no ano de 2009, conforme descreveu o Documento Base: Líneas de Desarrollo Estratégico, intensificam-se as ações com o objetivo de implantar o ENLACES, que adquire os primeiros contornos concretos de sua concepção: a) uma plataforma regional de conhecimento e informação e de integração do ensino superior para a América Latina e Caribe; b) um espaço de ações de cooperação solidária e de articulação entre instituições; c) uma instância de regulação de procedimentos e sugestões de normativas; e, d) um espaço de intercâmbios de experiências com base na mobilidade acadêmica e cooperação científica, e que utiliza tanto os elementos de interatividade virtual, como real, em prol da construção de um espaço de integração da educação superior capaz de criar vínculos entre os países da América Latina e Caribe.

O Documento Base estabeleceu, também, que o enlaces foi fundamentado nos seguintes acordos centrais: 1) que um primeiro conjunto de universidades que tenham adesão aos princípios da cres 2008, de diferentes países da América Latina e Caribe, e que cumpram com o requisito de serem equivalentes (desenvolvam ensino de graduação e de pós-graduação, pesquisa e extensão, com qualidade), constituam o grupo inicial do ENLACES, procurando fortalecer o ensino superior de caráter solidário com a incorporação de outras universidades e instituições que cumpram com esses requisitos; 2) que essas universidades estabeleçam programas acadêmicos em cursos de licenciatura, bacharelado, mestrado e doutorado com o objetivo de dar os primeiros passos para a criação de um sistema de créditos comuns, que possibilitarão transferências e reconhecimentos; e, 3) que todo o processo terá que ser coordenado pelos atores, ou seja, pelos reitores das universidades participantes.

Hoje o ENLACES está legalmente constituído, com seus Estatutos aprovados e que definem como finalidades "articular, integrar e representar a Educação Superior da América Latina e Caribe”. Os requisitos que devem ser atendidos para a adesão: "ser uma conferência nacional de reitores, organização regional de instituições de educação superior e/ou redes e ins- 
tituições de educação superior propriamente ditas, que compartilhem as finalidades, princípios e objetivos do ENLACES".

Desde o início das iniciativas que visavam à criação do ENLACES a UDUAL desempenhou expressivo papel protagonista, em total sintonia com suas origens e história. Criada tendo como uma das suas finalidades o apoio à integração acadêmica das universidades latino-americanas, atuou nas articulações entre instituições, organizou reuniões e eventos, produziu relatos e textos e assumiu responsabilidades quando o Espaço passou a funcionar efetivamente.

Coube à UDUAL constituir e coordenar o grupo inicial de universidades que participou do projeto piloto, cujo objetivo foi analisar as disciplinas e os programas de sete cursos de graduação (Administração, Enfermagem, Engenharia Civil, Filosofia, Física, Química e Matemática) para verificar as compatibilidades e a possível definição de uma metodologia para reconhecer créditos e títulos no âmbito dessas instituições de ensino superior. Compuseram o grupo as seguintes instituições: Universidade Estadual de Campinas, Universidade Federal de Minas Gerais, Universidad Nacional Autónoma de México, Universidad de Guadalajara, Universidad de La Habana, Pontificia Universidad Católica del Perú, Universidad Nacional de Avellaneda, Universidad Nacional de San Juan e Universidad de Panamá. No início dos trabalhos participou, também, a Universidad Nacional de Colombia. A reunião de instalação dos trabalhos ocorreu em junho de 2015, na Universidad do Panamá e os primeiros acordos foram concluídos recentemente.

\section{Os próximos anos}

A história está repleta de episódios em que a autonomia das universidades foi questionada, contestada e atacada. O ambiente universitário estimula a contestação, o contraditório e o livre debate das ideias. Esse é o contexto que permite criar condições para que o conhecimento novo seja produzido. Estímulo à ousadia é essencial. Governos baseados em regimes autoritários e intolerantes não sobrevivem por muito tempo se houver liberdade de expressão, são rapidamente contrariados por dados e argumentos científicos consistentes e não resistem ao debate intelectual constantemente promovido pelas universidades. Pela manutenção do poder agem na tentativa de silenciar vozes qualificadas, atacando o raciocínio lógico e fundamentado.

Recentemente o presidente da Sociedade Alemã de Amparo à Pesquisa, Peter Strohschneider, declarou: "Os regimes autocráticos temem a liberdade das ideias e o debate intelectual promovido nas universidades e vão sempre tentar restringir sua autonomia" (Pesquisa FAPESP, 2019, p. 35). Citou, também, alguns exemplos atuais de temas e países em que a intolerância dos governos provoca reflexos na autonomia universitária.

Acrescente-se, ainda, um alerta sempre atual e que foi expresso com muita clareza e propriedade por Dias Sobrinho:

A autonomia não é uma dádiva recebida pela universidade. Antes, é uma conquista que precisa ser assegurada permanentemente pela otimização do exercício das funções públicas e de responsabilidade social das universidades. As instituições precisam ser merecedoras da autonomia dian- 
te do Estado e das conexões dos poderes governamentais com o mercado. A defesa da autonomia é essencial para a sobrevivência da universidade pública. Mas só o real cumprimento das funções sociais da universidade poderá assegurar o reconhecimento e o respeito desse princípio por parte do Estado (2014, p. 178).

Muitos países consagraram o princípio da autonomia universitária como um dispositivo constitucional, tornando-o mais sólido e resistente às objeções populistas e autoritárias. Entretanto, em muitos outros, apenas dispositivos menores, como leis e decretos sustentam a vivência autônoma, enquanto ainda em vários não há regulamentos e a dependência da vontade dos governantes é a regra.

Há várias situações em que a autonomia está estabelecida no papel, mas os recursos destinados às instituições dependem completamente da boa vontade dos governantes. Não há autonomia plena sem financiamento adequado. A vinculação à arrecadação de impostos dos recursos destinados às universidades constitui medida adequada, estimulante da autonomia e representa, efetivamente, a possibilidade do pleno exercício do princípio da autonomia.

Assim, seja por causa das constantes ameaças ou para demostrar sua contribuição à sociedade, a autonomia universitária exige permanente estado de defesa, papel que a UDUAL deve e precisa continuar desempenhando. Ao mesmo tempo, deve contribuir para fortalecer, com argumentos e demonstrações das suas associadas, a luta para fazer constar dos textos constitucionais a garantia do princípio mais fundamental da existência de uma universidade, assim como a especificação dos recursos para o funcionamento adequado, vinculados à arrecadação dos impostos que a sociedade paga.

No que diz respeito à produção de conhecimento para benefício da sociedade, há muitos desafios a serem enfrentados. É inegável a necessidade de adequar o nível de financiamento existente, hoje muito abaixo do que seria razoável e esperado, para as ações de pesquisa e inovação. Uma região que abriga cerca de $6 \%$ da população mundial não pode contribuir com apenas pouco mais de $3 \%$ dos recursos mundiais destinados a essas atividades. O mesmo raciocínio aplica-se à questão da formação de recursos humanos qualificados, destinados ao desenvolvimento das atividades de pesquisa, inovação e colocação do conhecimento à disposição da sociedade. A formação de doutores e carreiras científicas claras e atraentes são urgentes para os países da América Latina. Verifica-se como uma questão de sobrevivência deixar de formar apenas poucas dezenas de doutores por milhão de habitantes por ano, como ocorre nos países da região, e passar para, pelo menos, uma centena, ou seja, no mínimo, dobrar o número de formados. Isso remete aos meios necessários para atingir esses números, que são os cursos de pós-graduação. Há necessidade de implantar programas em áreas emergentes, aperfeiçoar perfis existentes, melhorar a infraestrutura e ampliar a capacidade de formação de maneira significativa.

Não se trata apenas de ampliar investimentos. Existem outras ações, igualmente importantes, que produzem efeito catalisador no processo de formação de doutores. Alguns exemplos: a) doutorados conjuntos, ministrados por várias universidades, podendo criar áreas de excelência onde ainda não existem, a partir de grupos mais consolidados em outras universidades; b) 
projetos de pesquisa conjuntos, com características semelhantes ao item anterior e otimização dos investimentos; c) cursos temáticos de pós-graduação, congregando universidades de diferentes países em temas como segurança alimentar, energia, água, saneamento, violência, tecnologia da informação e outros; d) professores visitantes, intercâmbio de professores para formar grupos de pesquisa em suas áreas de especialidades em países distintos.

Para que essas iniciativas prosperem há necessidade de um agente articulador, que realize o papel de aproximar as instituições, proponha iniciativas concretas e busque agregar parceiros, públicos ou privados. Parece evidente a capacidade concentrada na UDUAL para realizar essa missão: 230 universidades e instituições de educação superior, localizadas em 22 países da América Latina e Caribe; cerca de 20 associações e redes universitárias; e 11 organismos de cooperação e estudos. Com a articulação da UDUAL esses atores do cenário acadêmico latino-americano poderão dar o necessário salto de qualidade e contribuir para que se alcancem resultados que coloquem a região em condições de produzir ciência e inovação de forma bem mais expressiva. Em algumas dessas questões a UDUAL já realizou atividades, iniciativas que precisam ser multiplicadas.

Em relação à integração acadêmica, não há dúvidas sobre o caminho a seguir. Prioridade absoluta para avançar com o ENLACES. É inadiável acelerar a sua implantação, ampliando o número de universidades envolvidas e estendendo a iniciativa a muitos outros cursos. Torna-se urgente definir uma metodologia que possa ser empregada de maneira geral para assegurar o reconhecimento de créditos e títulos entre as universidades dos distintos países da América Latina.

A mais recente iniciativa da União Europeia mostra como estamos muito distantes do patamar já atingido naquele continente. Em junho de 2019, foi anunciado o resultado da seleção realizada para estabelecer as primeiras dezessete universidades europeias. Estão envolvidas no projeto 114 instituições de educação superior da Europa, compondo as 17 universidades em 24 Estados-Membros da comunidade europeia. O objetivo da iniciativa, segundo a Comissão Europeia (2019), "é reunir uma nova geração de europeus criativos, capazes de pôr em prática uma cooperação transnacional, transdisciplinar e em línguas diferentes para fazer face aos grandes desafios societais e à escassez de competências com que a Europa se confronta". No comunicado à imprensa define-se a ideia conceitual:

As Universidades Europeias tornar-se-ão campus interuniversitários em torno dos quais os estudantes, os doutorandos, o pessoal e os investigadores podem circular sem barreiras. Reunirão os seus conhecimentos especializados, plataformas e recursos para a realização de programas ou módulos comuns que abranjam várias disciplinas. Estes programas serão muito flexíveis e permitirão aos estudantes personalizar a sua educação, escolhendo o que querem estudar, onde e quando fazê-lo, e onde obter um diploma europeu. As universidades europeias contribuirão também para o desenvolvimento econômico sustentável das regiões onde se encontram, uma vez que os seus estudantes irão trabalhar em estreita colaboração com empresas, autoridades municipais, académicos e investigadores para encontrar soluções para os desafios que as suas regiões enfrentam. 
Como se constata, há um longo caminho a percorrer em busca da integração acadêmica dos países latino-americanos. O tema, presente na origem da UDUAL, continua atual e necessitando de avanços rápidos.

Que a história e as iniciativas já vividas sirvam de estímulo para uma arrancada definitiva do ENLACES.

Uma questão essencialmente relevante deve ser sempre lembrada: a concepção e coordenação do Espaço são atribuições das universidades, pelo menos até a consolidação do processo, uma vez que é essencial que os conceitos fundamentais de sustentação do projeto tenham as corretas e necessárias bases acadêmicas e sejam governados pelos valores universitários. 


\section{Bibliografía}

Barro, Senén (coordinador). "La transferencia de I+D, la innovación y el emprendimiento en las universidades”. Educación superior em Iberoamérica. Informe 2015. Santiago de Chile, CINDA.

Cantard, Albor (2014). "La autonomía universitaria hoy. Um debate necessário”. In: Villar, Alejandro (compilador), La autonomía universitaria, uma mirada latinoamericana. Ciudad de México, UdUAL.

Clarivate Analytcs (2017). Research in Brazil, A report for CAPES. Disponível em: <https://www.capes.gov.br/images/stories/download/diversos/17012018-CAPES-InCitesReport-Final.pdf>.

Comissão Europeia (2019). Iniciativa Universidades Europeias. Disponível em; <https://ec.europa. eu/education/education-in-the-eu/european-education-area/european-universities-initiative_pt> e <https://europa.eu/rapid/press-release_IP-19-3389_pt.htm>.

Dias Sobrinho, José (2014). "Autonomia universitária: bem público e responsabilidade social". In Villar, Alejandro (compilador), La autonomía universitaria, uma mirada latinoamericana. Ciudad de México, udual.

Enlaces (2015). Documento Base. Disponível em: <http://espacioenlaces.org/wp-content/ uploads/2015/12/Documento-base-Lineas-para-el-desarrollo-Estrat\%C3\%A9gico-de-ENLACES..pdf $>$.

Enlaces (2016). Estatutos. Disponível em: <http://espacioenlaces.org/wp-content/ uploads/2018/08/ESTATUTO-ENLACES-web.pdf $>$.

Enlaces (2018). Informe del Comité Ejecutivo Provisional a la Primera Conferencia General Ordinaria. Disponível em: <http://espacioenlaces.org/wp-content/uploads/2018/07/ENLACES-informe-trayectoria.pdf $>$.

IESAlC-unesco (2008). Declaración y Plan de Acción de la Conferência Regional de Educación Superior em América Latina y el Caribe. Madrid, Ministerio de Ciencia e Innovación / Gobierno de España.

Martínez Durán, C. (1949). Discurso de bienvenida. Disponível em: <https://www.udual.org/ principal/wp-content/uploads/2019/06/Discurso-bienvenida1.pdf >.

Sánchez, Luis Alberto (1949). Proposición sobre autonomia! Disponível em: <https://www.udual. org/principal/wp-content/uploads/2019/06/Udual-15.pdf>.

Strohschneider, Peter (2019). "Entrevista”. Revista Pesquisa FAPESP, Ano 20, Número 280. Disponible en: <https://revistapesquisa.fapesp.br/en/2019/07/04/peter-strohschneider-freedom-to-seek-the-unknown/>.

Unión de Universidades Latinoamericanas (1949). Boletim Informativo, ano I, número 1. Disponível em: <https://www.udual.org/principal/wp-content/uploads/2019/06/Documento3.pdf>.

Unión de Universidades de América Latina y el Caribe (2012). "Declaración de Guadalajara sobre Autonomía Universitaria”. In Villar, Alejandro (compilador) (2014), La autonomía universitaria, uma mirada latinoamericana. Ciudad de México, UduAL.

Unión de Universidades de América Latina y el Caribe (2014). Estatutos. Disponível em: <https:// www.udual.org/principal/wp-content/uploads/2017/10/Estatutos-UDUAL-2016.pdf>.

Valadés, Diego (2014). “Autonomía y constitución em América Latina”. In Villar, Alejandro (compilador), La autonomía universitaria, uma mirada latinoamericana. Ciudad de México, UduAL. 